\title{
Vaginal misoprostol versus carbetocin in decreasing blood loss in abdominal momectomy : Randomized controlled trial
}

\section{Original Article}

\author{
Amro Salah Elhoussieny, Mohamed El-Mandooh Mohamed, Heba Abd El-Basset \\ Allam, Dina Atef Mahmoud Elmonirie Moustafa
}

Department of Obstetrics and Gynecology, Faculty of Medicine, Ain-Shams University, Egypt

\begin{abstract}
Background: Uterine fibroids are the most common female pelvic tumors occurring in about $15 \%$ to $30 \%$ of women in the reproductive age. When fibroids are associated with symptoms surgical intervention is often indicated.

Aim: The aim of the study is to evaluate the efficacy of administration of carbetocin in comparison to vaginal misoprostol in decreasing blood loss in women undergoing abdominal myomectomy.

Materials and Methods: The present study is a randomized controlled study carried out in Ain-Shams University Maternity Hospitals. The study included 44 women with age ranged from 25 to 40 years old, subjects were distributed randomly into two equal groups; group 1 included 22 patients who will receive $400 \mathrm{ug}$ misoprostol vaginally, one hour preoperative. Group 2 included 22 patients who will receive bolus of 100 ug carbetocin slowly intravenously once starting anesthesia.

Results: Laboratory investigations in this study revealed that there was no statistical significant difference between study groups as regards age, BMI and Parity, Preoperative hemoglobin and HCT $(P>0.05)$. As regards postoperative investigations of $\mathrm{Hb}$ and HCT highly statistical significant difference between study groups was found between both groups $(P<0.001)$. In comparing study groups there were no significant differences between women of both groups regarding estimated blood loss, postoperative $\mathrm{Hb}$, postoperative $\mathrm{HCT}$, calculated estimated blood loss, need for blood transfusion and hospital stay $(P>0.05)$.

Conclusion: These results showed no statistical difference was found between misoprostol and cabetocin groups in estimated blood loss, calculated estimated blood loss, need for blood transfusion and hospital stay.
\end{abstract}

Key Words: Abdominal myomectomy, carbetocin, misoprostol

Received: 6 November 2019, Accepted: 5 February 2020

Corresponding Author: Dina Atef Mahmoud, Department of Obstetrics and Gynecology, Faculty of Medicine, Ain-Shams University, Egypt, Tel.: 01112220298,E-mail: dinaatef779@gmail.com

ISSN: 2090-7265, November 2020, Vol. 10, No. 4

\section{INTRODUCTION}

Myomectomy is one of the curative treatment options for many uterine fibroids, but substantial intraoperative blood loss and the requirements for blood transfusion remain major consideration for abdominal myomectomy ${ }^{[13]}$.

Three common causes of increased blood loss during abdominal myomectomy are poor surgical technique, the complexity of intra-abdominal pathology (such as low corpus, intra- ligamentous myomas, or obliteration of culde-sac), and the excessive loss of intrauterine blood during dissection of the myomas.

Numerous strategies to reduce blood loss during abdominal myomectomy have been reported ${ }^{[13]}$.

Early reports described mechanical occlusion of the uterine arteries using myomectomy clamps and per cervical rubber tourniquet. GnRH agonists before surgery seem to be effective in some indications ${ }^{[9]}$.

Preoperative uterine artery embolization decreases blood loss during myomectomy, but this technique is restricted to particular hospital centers and can be complicated ${ }^{[9]}$.

Laparoscopic uterine artery occlusion has been described as a treatment for symptomatic myomas ${ }^{[6]}$.

Recent studies indicated that vaginal misoprostol was beneficial in significantly reducing perioperative blood loss during myomectomy. Despite these procedures, excessive hemorrhage during abdominal myomectomy remains a challenge to gynecologic surgeons ${ }^{[2]}$.

Misoprostol, a synthetic prostaglandin E1 analogue, apparently reduces to uterine blood flow, it stimulates uterine contractions and this leads to contraction of 
the vessels supplying blood to the leiomyomas. This subsequently may redistribute the blood from the diseased uterus back to the circulation, hence reducing operative blood loss during abdominal myomectomy, there is a moderate quality evidence that misoprostol reduces blood loss by between $70,24 \mathrm{ml}$ and $125.25 \mathrm{ml}$.

Carbetocin is a long- acting synthetic analogue of oxytocin with a half-life of 40 minutes and $80 \%$ bioavailability in IM injection. After IM or IV administration of this drug, uterine contractions start in less than 2 minutes. Carbetocin makes a longer uterine response compared with oxytocin in terms of frequency and amplitude of contractions ${ }^{[6]}$.

Recent studies showed that oxytocin infusion and carbetocin may be beneficial in reducing blood loss during myomectomy ${ }^{[15]}$

\section{AIM OF THE STUDY}

The aim of the work is to evaluate the efficacy of administration of carbetocin in comparison to vaginal misoprostol in decreasing blood loss in women undergoing abdominal myomectomy.

\section{PATIENTS AND METHODS}

This study is a randomized controlled study and was carried out in Ain-Shams University Maternity Hospitals. The study included 44 women with age range (25-40 years) who were distributed randomly into two groups, each containing 22 women; group 1 included patients who received 400 ug misoprostol vaginally, one hour preoperative and group 2 included patients who received bolus of 100 ug carbetocin slowly intravenous once starting the anesthesia.

Patients were enrolled in the study according to the following criteria: All women requiring abdominal myomectomy for symptomatic leiomyomas were invited to participate in the study when they attended the outpatient assessment clinic. The fibroids were interstitial ranging in number from one to five and in size from 5 to $15 \mathrm{cms}$.

All patients with the following criteria were excluded from the study: Any contraindication to misoprostol, including mitral stenosis, glaucoma, sickle cell anemia, diastolic blood pressure over $100 \mathrm{mmHg}$, severe asthma, or known allergy to prostaglandin. Any contraindication to carbetocin, hypersensitivity to carbetocin, hepatic or renal diseases, serious cardiovascular problems, epilepsy. Obese patients (body mass index $>30 \mathrm{~kg} / \mathrm{m} 2$ ). A known history of pelvic or ovarian endometriosis. A known history of active medical disease e.g. hypertension, DM, coagulative disorders. Previous myomectomy. Women who had pre- operative hormonal therapy (mifepristone, GnRH analog or oral contraceptive pills) that could affect intraoperative bleeding. Women with mental impairment or incompetent in giving consent.

\section{Methodology : After approval of ethical committee:}

Before surgery all patients underwent routine preoperative assessments including pelvic ultrasonography. All patients were screened for cervical intraepithelial neoplasia (CIN). For all participants, blood samples were taken and complete blood count (CBC) was done.

All patients received prophylactic antibiotics (2gms ceftriaxone IV within 30 minutes before the operation). Blood pressure, pulse rate and temperature were recorded at the time of admission and immediately before induction of anesthesia. Women were distributed into two groups; group 1 received 400ug misoprostol (two tablets) vaginally one hour preoperative and group 2 received 100ug carbetocin slowly intravenous over minute once starting the anesthesia, ampoules were stored at refrigerator temperature $\left(2-8^{\circ} \mathrm{C}\right)$ protected from light.

\section{Steps of abdominal myomectomy:}

- Abdominal myomectomy was performed by the usual standard surgical technique.

- Sterilisation, catheterization and toweling.

- Pfannestiel skin incision.

-The uterus was exposed and the bowel was packed off.

- An incision was made in the serosal surface of the uterus through the myometrium down to the myoma.

-A finger or haemostatic forceps was used to sweep the myometrium off the fibroid.

-A towel clip was used to grasp the fibroid and counter traction was used to elevate the fibroid out the myometrium, the tumor was removed by an electrocautry.

-If excessive myometrium was present, it was trimmed away.

-The myometrium was closed in two layers with 20- vicryl.

-Closure of anterior abdominal wall in layers.

-All of the patients' sociodemographic characteristics, as well as the number and size of preoperative myomas; operation time; preoperative and postoperative hemoglobin and hematocrit values; intraoperative blood loss; need for intraoperative and postoperative blood transfusion; side effects of the drugs and the period of hospitalization were calculated.

The number and localization of myomas and the largest myoma diameter were established by ultrasonography.

Estimation of blood loss, the amount of blood accumulated in the aspiration equipment as the basis for calculating the patient's blood loss during the operation 
was measured, and the amount of blood on the surgical towel. The total volume of intraoperative blood loss was estimated by:

1- Weighing the dry towel.

2- Weighing blood soaked towel as soon as they are discarded and subtract their dry weight $(1 \mathrm{ml}$ of blood weighs approximately $1 \mathrm{gm}$ ).

3- Subtract the weight of empty aspiration equipment from filled ones.

4- Estimate blood loss into surgical drapes, together with pooled blood beneath the patient onto the floor.

5 - Note the volume of irrigation fluids; subtract this volume from the measured blood loss to estimate the final blood loss.

\section{STATISTICAL ANALYSIS:}

Statistical analysis was performed using Microsoft Excel version 2010 and SPSS for Windows version 20.0. Data was presented as number and percentage (for categorical variables); range, mean and standard deviation (for numeric parametric variables); or range, median and interquartile range (for numeric nonparametric variables). Difference between two groups was analyzed using chi-squared test (for categorical variables); independent student's t-test (for numeric parametric variables); or Mann-Whitney's U-test (for numeric nonparametric variables). Significance level is set at 0.05 .

\section{RESULTS}

There were no significant differences between women of both groups regarding age, parity and BMI (Table 1).

There were no significant differences between women of both groups regarding largest myoma dimension, preoperative hemoglobin concentration and preoperative hematocrit (Table 2).

There was a statistically significant difference between postoperative and preoperative $\mathrm{Hb}$ and HCT values in both groups (Table 3 ).

There were no significant differences between women of both groups regarding estimated blood loss, postoperative $\mathrm{Hb}$, postoperative $\mathrm{HCT}$, calculated estimated blood loss, need for blood transfusion and hospital stay (Table 4).

Table 1: Difference between Groups regarding Initial Characteristics

\begin{tabular}{|c|c|c|c|c|}
\hline & $\begin{array}{c}\text { Group I } \\
\text { [Misoprostol Group] } \\
(\mathrm{n}=22)\end{array}$ & $\begin{array}{c}\text { Group II } \\
\text { [Carbetocin Group] } \\
(\mathrm{n}=22)\end{array}$ & $\underset{(95 \% \mathrm{CI})}{\mathrm{MD}}$ & $P$ \\
\hline \multicolumn{5}{|l|}{ Age (years) } \\
\hline Range & $24-40$ & $25-40$ & 1.95 & 0.161 \\
\hline Mean \pm SD & $33.55 \pm 4.67$ & $35.5 \pm 4.45$ & $(-4.72$ to 0.81$)$ & NS \\
\hline Parity & & & 0.14 & 0.726 \\
\hline Range & $0-5$ & $0-4$ & $(-0.65$ to 0.92$)$ & NS \\
\hline \multicolumn{5}{|l|}{ BMI (kg/m2) } \\
\hline Range & $23.44-30$ & $25.71-29.33$ & -0.69 & 0.132 \\
\hline Mean \pm SD & $27.58 \pm 1.73$ & $28.27 \pm 1.18$ & ( -1.59 to 0.22$)$ & NS \\
\hline
\end{tabular}

SD standard deviation - IQR interquartile range - BMI body mass index

Analysis using unpaired student's t-test

MD $(95 \% \mathrm{CI})$ mean difference and its $95 \%$ confidence interval

NS non-significant

$P$ values : NA 
Table 2: Difference between Groups regarding Pre-Operative Data

\begin{tabular}{|c|c|c|c|c|}
\hline & $\begin{array}{c}\text { Group I } \\
\text { [Misoprostol Group] } \\
(\mathrm{n}=22)\end{array}$ & $\begin{array}{c}\text { Group II } \\
\text { [Carbetocin Group] } \\
(\mathrm{n}=22)\end{array}$ & $\begin{array}{c}\mathrm{MD} \\
(95 \% \mathrm{CI})\end{array}$ & $P$ \\
\hline \multicolumn{5}{|c|}{$\begin{array}{l}\text { Largest Myoma } \\
\text { Dimension }\end{array}$} \\
\hline Range & $5.0-10.5$ & $5.0-15.0$ & 0.09 & 0.892 \\
\hline Mean \pm SD & $7.41 \pm 1.89$ & $7.32 \pm 2.47$ & $(-1.25$ to 1.43$)$ & NS \\
\hline \multicolumn{5}{|c|}{ Preoperative $\mathrm{Hb}$ (g/dl) } \\
\hline Range & $10.1-13.5$ & $10.0-13.9$ & -0.37 & 0.369 \\
\hline Mean \pm SD & $11.39 \pm 1.34$ & $11.76 \pm 1.38$ & $(-1.2$ to 0.46$)$ & NS \\
\hline \multicolumn{5}{|c|}{ Preoperative HCT } \\
\hline Range & $30.3-42.0$ & $30.2-42.7$ & -0.80 & 0.504 \\
\hline Mean \pm SD & $35.96 \pm 3.76$ & $36.76 \pm 4.15$ & $(-3.21$ to 1.61$)$ & NS \\
\hline
\end{tabular}

SD standard deviation - IQR interquartile range - Hb Hemoglobin - HCT hematocrit

Analysis using unpaired student's t-test

MD $(95 \% \mathrm{CI})$ mean difference and its $95 \%$ confidence interval

NS non-significant

$P$ values : NA

Table 3: Difference between Pre- and Postoperative Hb and HCT among Women of Group I [Misoprostol Group] and group II [Carbetocin Group]

\begin{tabular}{|c|c|c|c|c|}
\hline $\begin{array}{l}\text { Group I } \\
\text { [Misoprostol Group] } \\
(\mathrm{n}=22)\end{array}$ & Preoperative & Postoperative & $\begin{array}{c}\text { MPD } \\
(95 \% \mathrm{CI})\end{array}$ & $P$ \\
\hline \multicolumn{5}{|l|}{$\mathrm{Hb}(\mathrm{g} / \mathrm{dl})$} \\
\hline Range & $10.1-13.5$ & $8.3-12.5$ & 0.65 & $<0.001$ \\
\hline Mean \pm SD & $11.39 \pm 1.34$ & $10.74 \pm 1.29$ & $(0.43$ to 0.87$)$ & HS \\
\hline \multicolumn{5}{|l|}{ HCT } \\
\hline Range & $30.3-42.0$ & $26.3-39.1$ & 2.55 & $<0.001$ \\
\hline Mean \pm SD & $35.96 \pm 3.76$ & $33.41 \pm 4.11$ & (1.69 to 3.40$)$ & HS \\
\hline \multicolumn{5}{|l|}{$\begin{array}{l}\text { Group II [Carbetocin } \\
\text { Group] }(n=22)\end{array}$} \\
\hline \multicolumn{5}{|l|}{$\mathrm{Hb}(\mathrm{g} / \mathrm{dl})$} \\
\hline Range & $10.0-13.9$ & $8.2-12.8$ & 1.14 & $<0.001$ \\
\hline Mean \pm SD & $11.76 \pm 1.38$ & $10.62 \pm 1.35$ & (0.66 to 1.62$)$ & $\mathrm{HS}$ \\
\hline \multicolumn{5}{|l|}{$\mathrm{HCT}$} \\
\hline Range & $30.2-42.7$ & $23.3-40.8$ & 3.46 & $<0.001$ \\
\hline Mean $\pm \mathrm{SD}$ & $36.76 \pm 4.15$ & $33.3 \pm 4.84$ & $(2.22$ to 4.69$)$ & HS \\
\hline
\end{tabular}

SD standard deviation - IQR interquartile range - Hb Hemoglobin - HCT hematocrit

Analysis using paired student's t-test

MPD (95\% CI) mean paired difference and its 95\% confidence interval

HS highly significant

$P$ values : NA 
Table 4: Difference between Groups regarding Intra- and Post-Operative Data

\begin{tabular}{|c|c|c|c|c|}
\hline & $\begin{array}{c}\text { Group I } \\
\text { [Misoprostol Group] } \\
(\mathrm{n}=22)\end{array}$ & $\begin{array}{c}\text { Group II } \\
\text { [Carbetocin Group] } \\
(\mathrm{n}=22)\end{array}$ & $\begin{array}{c}\mathrm{MD} \\
(95 \% \mathrm{CI})\end{array}$ & $P$ \\
\hline \multicolumn{5}{|c|}{$\begin{array}{l}\text { Estimated Blood } \\
\text { Loss }(\mathrm{ml})\end{array}$} \\
\hline Range & $400-1200$ & $400-1000$ & -22.7 & $0.730^{1}$ \\
\hline Mean \pm SD & $677.3 \pm 240.9$ & $700.0 \pm 189.6$ & $(-154.9$ to 109.5$)$ & NS \\
\hline \multicolumn{5}{|c|}{ Post-Operative $\mathrm{Hb}(\mathrm{g} / \mathrm{dl})$} \\
\hline Range & $8.3-12.5$ & $8.2-12.8$ & 0.12 & 0.769 \\
\hline Mean \pm SD & $10.74 \pm 1.29$ & $10.62 \pm 1.35$ & $(-0.69$ to 0.93$)$ & NS \\
\hline \multicolumn{5}{|c|}{ Post-Operative HCT } \\
\hline Range & $26.3-39.1$ & $23.3-40.8$ & 0.10 & 0.939 \\
\hline Mean \pm SD & $33.41 \pm 4.11$ & $33.3 \pm 4.84$ & $(-2.63$ to 2.84$)$ & NS \\
\hline \multicolumn{5}{|c|}{$\begin{array}{l}\text { Need for Blood } \\
\text { Transfusion }\end{array}$} \\
\hline None & $21(95.5 \%)$ & $21(95 \%)$ & & \\
\hline 1 unit & $0(0 \%)$ & $1(4.5 \%)$ & & $0.368^{2}$ \\
\hline 2 units & $1(4.5 \%)$ & $0(0 \%)$ & & NS \\
\hline \multicolumn{5}{|c|}{ Operative Time (mins) } \\
\hline Range & $80-140$ & $90-135$ & -1.36 & 0.758 \\
\hline Mean \pm SD & $111.82 \pm 16.51$ & $113.18 \pm 12.30$ & $(-10.22$ to 7.49$)$ & NS \\
\hline \multicolumn{5}{|c|}{ Hospital Stay (days) } \\
\hline Range & $2-4$ & $2-4$ & 0.23 & 0.347 \\
\hline Mean \pm SD & $3.1 \pm 0.75$ & $2.86 \pm 0.83$ & $(-0.26$ to 0.71$)$ & NS \\
\hline
\end{tabular}

SD standard deviation - IQR interquartile range $-\mathrm{Hb}$ Hemoglobin - HCT hematocrit

1 Analysis using unpaired student's t-test

2 Analysis using chi-square test

MD $(95 \% \mathrm{CI})$ mean difference and its $95 \%$ confidence interval

NS non-significant

$P$ values : NA

Table 5: Difference between the two groups regarding side effects

\begin{tabular}{lccccc}
\hline \multirow{2}{*}{ Side effects } & Group I & \multicolumn{2}{c}{ Group II } & \multicolumn{2}{c}{ P-value } \\
\hline Nausea & No & $\%$ & No & $\%$ & 0.550 \\
Vomiting & 2 & $9.1 \%$ & 1 & $4.5 \%$ & - \\
Fever & 0 & $0.0 \%$ & 0 & $0.0 \%$ & - \\
Chills & 0 & $0.0 \%$ & 0 & $0.0 \%$ & - \\
Diarrhea & 0 & $0.0 \%$ & 0 & $0.0 \%$ & - \\
\hline
\end{tabular}

$P$ values : NA 


\section{DISCUSSION}

The present study is a randomized controlled study carried out in Ain-Shams University Maternity Hospitals. The study included 44 women with age ranged from 25 to 40 years old, subjects were distributed randomly into two equal groups: group 1 included 22 patients who received 400 ug misoprostol vaginally, one hour preoperative. While, group 2 included 22 patients who received bolus of $100 \mathrm{ug}$ carbetocin slowly intravenously once starting anesthesia.

The aim of the study is to evaluate the efficacy of administration of carbetocin in comparison to vaginal misoprostol in decreasing blood loss in women undergoing abdominal myomectomy.

The present study results showed that there were no significant differences between both groups regarding age, parity and BMI $(P=0.161,0.726$ and 0.059, respectively). Similarly, Nankali et al. ${ }^{[10]}$ single-blinded randomized controlled trial included 60 patients who were candidates for total abdominal hysterectomy due to uterine fibroid or abnormal uterine bleeding. The patients were divided into two groups; the first group received misoprostol $400 \mathrm{mcg}$ (30 cases) and the second group received vitamin B6 (30 cases) once sublingually 1 hour before TAH serving as controls,

The results revealed that there were no significant differences between both groups regarding age, weight, height, BMI, parity and gravity $(P>0.05)$. This was in agreement with Larciprete et al. ${ }^{[8]}$ prospective case-control study that included 102 women who were divided into 2 groups carbetocin group (group A) received a bolus of $100 \mu \mathrm{g} \mathrm{IV}$. Women in the control group (group B) received 20 IU of oxytocin in $1000 \mathrm{ml}$ of $0.9 \% \mathrm{Na}-\mathrm{Cl}$ solution IV $(150 \mathrm{~mL} /$ hour $)$ and found that there was no significant difference between study groups regards age and weight $(P=0.33$ and 0.15$)$.

The study results of preoperative data showed that there were no significant differences between both groups regarding largest myoma dimension, preoperative hemoglobin concentration and hematocrit $(P=0.892,0.369$ and 0.504 , respectively), while in comparing the laboratory results of postoperative and preoperative $\mathrm{Hb}$ and $\mathrm{HCT}$ values in patients who received misoprostol (group 1), it was found that the level of hemoglobin concentrations decreased after myomectomy (mean level=10.74 $\pm 1.29 \mathrm{~g} / \mathrm{dl}$ ) than pre-operation level (mean level $=11.39 \pm 1.34$ $\mathrm{g} / \mathrm{dl})$ with highly statistical significant difference between both $(p<0.001)$. Also, the level of HCT showed a significant decrease after myomectomy from $35.96 \pm 3.76$ to $33.41 \pm 4.11(P<0.001)$. Nankali et al. ${ }^{[10]}$ trial's results showed that hemoglobin level 24 hours after total abdominal hysterectomy (TAH) had a higher mean value in the misoprostol group $(11.72 \mathrm{~g} / \mathrm{dl})$ than in the control group $(10.54 \mathrm{~g} / \mathrm{dl})(P=0.003)$.

Two studies have investigated pre-operative sublingual misoprostol for blood loss during total abdominal hysterectomy $\mathrm{TAH}^{[3]}$. One of these trials ${ }^{[3]}$ which recruited 132 women undergoing TAH and administered 400 mcg misoprostol 30 minutes before TAH concluded that the group for which misoprostol was used had lower blood loss (356 mL) compared to placebo group $(435 \mathrm{~mL})$. The authors concluded that misoprostol was an effective intervention for reducing blood loss during TAH. However, the other trial ${ }^{[5]}$ studying 32 women with the same dose of misoprostol and the same administration route did not support the beneficial effect of misoprostol.

The results of the present study in carbetocin patients (group 2) revealed that there were highly statistical significant differences between both levels of hemoglobin and HCT before and after myomectomy groups ( $P<0.001$ for both). Sallam and Shady ${ }^{[1]}$ carried out a randomized double-blind placebo controlled trial included 86 women undergoing abdominal myomectomy for symptomatic uterine leiomyomas who were randomly assigned to receive a single dose of pre-operative of IV $100 \mu \mathrm{g}$ carbetocin $(\mathrm{n}=43)$ or placebo $(n=43)$ just before the operation. The results showed that when comparing the pre-operative and postoperative hemoglobin and as secondary outcomes observing the change in hemoglobin and was lower in the study group but not reach statistical significance $(P>0.05)$. While, Allah et al. ${ }^{[1]}$ showed in their study significant decrease of post-operative $\mathrm{HB}$ in control group $(P<0.05)$.

The current study results showed that there were no significant differences between the study groups regarding estimated blood loss $(P=0.730)$, postoperative hemoglobin $(P=0.769)$, postoperative HCT $(P=0.939)$, calculated estimated blood loss $(P=0.165)$, need for blood transfusion $(P=0.368)$ and hospital stay $(\mathrm{P}=0.939)$. This comes with the results of El Sharkway (2013) in his randomized study on 380 patients who were randomly allocated to receive either combined $400 \mu \mathrm{g}$ sublingual misoprostol before surgery plus 20 IU oxytocin after delivery of baby $(n=190)$ or intravenous $100 \mu \mathrm{g}$ carbetocin $(n=190)$. The results revealed that $16.3 \%$ of women who received sublingual misoprostol plus oxytocin infusion required additional uterotonic versus $13.7 \%$ of the women who received 
intravenous carbetocin with no significant difference $(p=0.27)$. No significant difference between treatment groups in preoperative and postoperative hemoglobin level change, estimated blood loss, incidence of blood transfusion was observed $(P>0.05)$.

Nankali et al. ${ }^{[10]}$ reported that mean $( \pm \mathrm{SD})$ blood loss volume was significantly lower in misoprostol group $(370.13 \pm 158.84 \mathrm{ml})$ compared to control group $(466 \pm 204.7 \mathrm{ml})(P=0.046)$ and the mean hospital stay duration was shorter in the misoprostol group ( $3.25 \pm 1.32$ days) vs. control group (3.43 \pm 0.5 days $),(P=0.003)$ but no significant difference was observed regarding need for blood transfusion during the operation between misoprostol (1/30 patients) vs. control group (4/30 patients). The study concluded that sublingual misoprostol $(400 \mathrm{mcg})$ administered 1 hour before TAH was effective in reducing blood loss volume, hemoglobin drop and hospitalization duration.

Larciprete et al. ${ }^{[8]}$ study results showed that there was no significant difference between the study groups regarding $\mathrm{HCT}$, PLT and $\mathrm{Hb}$ concentrations $(P=0.80,0.09$ and 0.33 , respectively) .

Sallam and Shady ${ }^{[11]}$ results showed that intraoperative blood loss was significantly lower in those women randomized to receive IV carbetocin versus the placebo group $(714.19 \pm 186.27 \mathrm{ml}$ versus $1033.49 \pm 140.9 \mathrm{ml}),(p=0.0001)$. Also, the incidence of blood transfusion was increased in placebo group (69.8\%) compared with (18.6\%) in carbetocin group, $(P=0.0001)$ and there was a significant reduction in operative time in carbetocin group $(66.35 \% \pm 10.18)$ compared with placebo group $(95.95 \pm 9.16),(P=0.0001)$.

One of the strength of Sallam and Shady ${ }^{[11]}$ study was that double blind randomized study provides the first evidence that a IV carbetocin a simple alternative preemptive intervention for reduced intraoperative blood loss and need of blood transfusion during abdominal myomectomy. Another strength was as the average amount of blood loss was the primary outcome of this research, study power was calculated online was found to be $100 \%$.

Yang et al..$^{[15]}$ compare carbetocin versus oxytocin in decrease blood loss during laparoscopic myomectomy and concluded that giving carbetocin preoperatively to laparoscopic myomectomy patients had good clinical efficacy, bringing about less blood loss, shorter operative time and rapid postoperative recovery. It is, therefore considered safe and reliable and worthy of clinical applications.
Allah et $a{ }^{[1]}{ }^{[1]}$ study the effect of intra-myometrial carbetocin injection in reducing intraoperative blood loss during myomectomy and conclude that Injection of intra- myometrial carbetocin was associated with less blood loss during myomectomy. Moreover, it may lower the need for blood transfusion. Patients in whom carbetocin was used showed lower drop in their hemoglobin and hematocrit levels when measured 48 hours postoperatively.

A single pre-operative dose of IV carbetocin is a simple, cost effective method for reducing intraoperative blood loss and operative time in abdominal myomectomy. Investigation of carbetocin use in larger population groups and with different dosages and another route together with comparison of other methods used to reduce bleeding during myomectomy is required.

Larciprete et al. ${ }^{[8]}$ study results suggested the effectiveness of carbetocin compared to oxytocin regarding the uterine contraction and tonicity. Also. the uterine contractility was better in the carbetocin group at 2, 12 and 24 hours after caesarean section as well as the fundus was significantly below $2 \mathrm{~cm}$ from the umbilical point (-2UP) in patients of group A after 2 and 12 hours. Larciprete et al., concluded that a single injection of carbetocin appears to be more effective than a continuous infusion of oxytocin to maintain adequate uterine tone with a similar safety profile and minor antidiuretic effect in the third stage and in the first 24 hours after delivery defined as four stage of labor ${ }^{[4]}$.

Yanjun ${ }^{[16]}$ case control study on 78 pregnant women with high risk of postpartum hemorrhage were divided into control group and observation group randomly (40 cases in observation group applied carbetocin during operation for prevention and 38 cases in control group were routinely treated with oxytocin). The hemorrhage volume during operation and at $24 \mathrm{~h}$ after operation were compared between the two groups and results showed that the bleeding volume during operation and at $24 \mathrm{~h}$ after operation in the observation was significantly lower than that in the control group with statistical difference $(P=0.01)$.

Shen et al. ${ }^{[12]}$ study on 85 patients who underwent laparoscopic myomectomy with carbetocin $(\mathrm{n}=30)$ or oxytocin $(\mathrm{n}=28)$ during operation were analyzed and the results showed that the mean blood loss in operation of the carbetocin group were significantly less than that of the oxytocin group $(111 \pm \mathrm{s} 35) \mathrm{ml}$ vs. $(160 \pm 49) \mathrm{ml}(P=0.01)$. The mean reduce of hemoglobin of the carbetocin 
group were also less than that of the oxytocin group $(13 \pm 8) \mathrm{g} / \mathrm{dl}$ vs. $(18 \pm 10) \mathrm{g} / \mathrm{dl}(P 0.05)$ but there was no significant difference in operation time between the two groups 12333 ) $\mathrm{min}$. vs. $128 \pm 30 \mathrm{~min}$. ( $P$ 0.05) study concluded carbetocin may stimulate contraction of the uterus and reduce blood loss during laparoscopic hysterectomy.

\section{CONCLUSION}

This study is a randomized controlled study, and was carried out in Ain-Shams University Maternity Hospitals. It was carried out to determine and to compare the effects of carbetocin and vaginal misoprostol in reducing blood loss during abdominal myomectomy. The results showed no statistical difference was found between misoprostol and cabetocin groups in estimated blood loss, calculated estimated blood loss, need for blood transfusion and hospital stay.

\section{CONFLICT OF INTEREST}

There are no conflicts of interests.

\section{REFERENCES}

1. Allah G, Sherine H, Wali A, Mostafa A, Shimaa F (2015): Hemostatic effect and postoperative benefits of intramyometrial Carbetocin injection during myomectomy: a randomized controlled trial. Evidence Based Women's Health $\mathrm{J} ; 5(4): 185-9$

2. Atashkhoei S, Fakhari S, Pourfathi H, Bilehjani E, Garabaghi PM, Asiaei A (2016): Effect of oxytocin infusion on reducing the blood loss during abdominal myomectomy: a double-blind randomised controlled trial. BJOG; 124:292-8

3. Biswas J, Chaudhuri P, Mandal A, Bandyopadhyay SN, Dasgupta S, Pal A (2013): Effect of a single preoperative dose of sublingual misoprostol on intraoperative blood loss during total abdominal hysterectomy. Int $\mathrm{J}$ Gynaecol Obstet; 122(3):244-7

4. Borruto F, Treisser A, Comparetto C (2009): Utilization of carbetocin for prevention of postpartum hemorrhage after cesarean section: a randomized clinical trial. Arch Gynecol Obstet; 280:707-12.

5. Chai J, Hon E, Li CF, Pun TC, Yeung SB, Ho PC (2011): A pilot study of pre-operative misoprostol in reducing operative blood loss during hysterectomy. Eur J Obstet Gynecol Reprod Biol; 158(1):72-5.
6. Chang WC, Chou LY, Chang DY, Huang PS, Huang SC, Chen SY, et al. (2011): Simultaneous laparoscopic uterine artery ligation and laparoscopic myomectomy for symptomatic uterine myomas with and without in situ morcellation, Hum Reprod, 26: 1735-1740.

7. Kongnyuy EJ and Wiysonge CS (2014): Interventions to reduce haemorrhage during myomectomy for fibroids. Cochrane Database Syst Rev; 8:CD005355.

8. Larciprete G, Montagnoli C, Frigo M, Panetta V, Todde C, Zuppani B and Valensise H (2013): Carbetocin versus oxytocin in caesarean section with high risk of post-partum haemorrhage. Journal of Prenatal Medicine, 7(1): 12.

9. Lin JY, Lee WL, Wang PH, Lai MJ, Chang WH, Liu WM (2010): Uterine artery occlusion and myomectomy for treatment of pregnant women with uterine leiomyomas who are undergoing Cesarean section J Obstet Gynaecol Res, 36: 284290-.

10. Nankali A, Fakheri T, Hematti $M$ and Noori $T$ (2017): Pre-operative sublingual misoprostol and intra-operative blood loss during total abdominal hysterectomy: a randomized single-blinded controlled clinical trial. World Family Medicine, 15(7): 3539-.

11. Sallam HF and Shady NW (2018): Intravenous Carbetocin to decrease blood loss during open myomectomy: a randomized placebocontrolled study. International Journal of Reproduction, Contraception, Obstetrics and Gynecology, 7(1): 28.

12. Shen Y, Xiong ZF, Min J, Wang ZH (2009): Application of carbetocin in reducing hemorrhage during laparoscopic myomectomy $[\mathrm{J}]$. Chinese Journal of New Drugs and Clinical Remedies, 12.

13. Thomas RL, Winkler N, Carr BR, Doody KM, Doody KJ (2010): Abdominal myomectomy-a safe procedure in an ambulatory setting. Fertil Steril, 94: 2277-2280.

14. Wang CJ, Yuen LT, Lee CL, Kay N, Soong YK (2006): A prospective comparison of morcellator and culdotomy for extracting of uterine myomas laparoscopically in nullipara $\mathrm{J}$ Minim Invasive Gynecol, 13:463-466.

15. Yang JH, Chen MJ, Chen CD, Chen CL, Ho HN, Yang YS (2012): Impact of submucous myoma on the severity of anemia. Fertil Steril; 95: 1769-1772.e1 
16. Yanjun Z(2012): Clinical observation of carbetocin for preventing and treating intraoperative and postoperative hemorrhage in cesarean section $[\mathrm{J}]$. Journal of Modern Medicine \& Health, 21. 